\title{
DESEMPENHO dE REATOR ANAERÓBIO-AERÓBIO DE LEITO FIXO NO TRATAMENTO DE ESGOTO SANITÁRIO
}

\section{Performance of ANAERobic-Aerobic PACKed-Bed ReACtOR IN THE TREATMENT OF DOMESTIC SEWAGE}

\author{
SÉRGIO BRASIL ABREU \\ Engenheiro Civil (UFC). Mestre em Engenharia Hidráulica e Saneamento (EESC/USP). \\ Doutorando em Engenharia Sanitária (EP/USP)
}

\begin{abstract}
MARCELO ZAIAT
Engenheiro Químico (UFSCar). Doutor em Engenharia Hidráulica e Saneamento (EESC/USP). Professor Associado do Departamento de Hidráulica e Saneamento (EESC/USP)
\end{abstract}

Recebido: 27/02/07 Aceito: 16/04/08

\section{RESUMO}

Este artigo relata a avaliação do desempenho de um reator anaeróbio-aeróbio, preenchido com espuma de poliuretano, para tratamento de esgoto sanitário. Inicialmente, foram testados diferentes tempos de detenção hidráulica $(\mathrm{TDH})$ no reator que operou apenas em condiçôes anaeróbias. Em seguida, foi operado o reator combinado anaeróbio-aeróbio. O melhor resultado para o reator em operação exclusivamente anaeróbia foi para o TDH de 10 horas, no qual se conseguiu reduzir a DQO de $389 \pm 70 \mathrm{mg} / \mathrm{L}$ para $137 \pm 16 \mathrm{mg} / \mathrm{L}$. Para o reator anaeróbio-aeróbio, a DQO foi reduzida de $259 \pm 69 \mathrm{mg} / \mathrm{L}$ para $93 \pm 31 \mathrm{mg} / \mathrm{L}$ para TDH de 12 h (6 h no estágio anaeróbio e $6 \mathrm{~h}$ no aeróbio). A comparação de todos os resultados obtidos evidenciou a importância do pós-tratamento aeróbio na remoção de parcela de matéria orgânica não removida em tratamento unicamente anaeróbio.

PALAVRAS-CHAVE: Reator de leito fixo, escoamento ascendente, esgoto sanitário, biomassa imobilizada, espuma de poliuretano, tratamento anaeróbio-aeróbio.

\begin{abstract}
This paper reports on the performance evaluation of an upflow anaerobic-aerobic reactor, filled with polyurethane matrices, for domestic sewage treatment. Initially, different hydraulic retention times were assayed with the reactor operating exclusively in anaerobic condition. Afterwards, anaerobic-aerobic combined reactor was operated. The anaerobic operation with HRT of $10 \mathrm{~h}$ provided the best organic matter removal with COD reduction from $389 \pm 70 \mathrm{mg} / \mathrm{L}$ to $137 \pm 16 \mathrm{mg} / \mathrm{L}$. Under anaerobic-aerobic condition, the COD dropped from $259 \pm 69 \mathrm{mg} / \mathrm{L}$ to $93 \pm 31 \mathrm{mg} / \mathrm{L}$ with HRT of $12 \mathrm{~h}$ (6 $\mathrm{h}$ in anaerobic and $6 \mathrm{~h}$ in aerobic stages). Finally, comparing all the obtained results, it was possible to verify the importance of the aerobic post treatment in the removal of part of the organic matter not removed in an exclusively anaerobic treatment.
\end{abstract}

KEYWORDS: Fixed-bed upflow reactor, domestic sewage, immobilized biomass, polyurethane foam, anaerobic-aerobic treatment.

\section{INTRODUÇÃO}

Durante muito tempo acreditouse que a aplicação de processos anaeróbios não seria boa alternativa para o tratamento de águas residuárias. Com o passar dos anos, muitas pesquisas foram realizadas nessa área e constatou-se que os processos anaeróbios, se projetados com responsabilidade e bem operados, apresentam bons resultados. No entanto, muitos países ainda se encontram reticentes quanto ao seu uso devido aos resíduos orgânicos que ainda se fazem presentes após essa unidade de tratamento (Bodik et al, 2003).

Tanto países em desenvolvimento, que possuem baixo poder aquisitivo, como também nações desenvolvidas, que apresentam pequenas áreas disponíveis em seus centros urbanos podem fazer uso da tecnologia anaeróbia. Seu uso vem sendo cada vez mais bem aceito pela comunidade, mostrando assim, a viabilidade dessa alternativa.

A retenção de biomassa ativa no interior de reatores anaeróbios é fator decisivo para o sucesso do processo de tratamento e depende de vários fatores operacionais e ambientais. A perda da biomassa com o efluente influencia negativamente o desempenho do tratamento. Uma forma de se evitar essa perda é sua imobilização em material suporte, formando os biofilmes. Assim, desvincula-se efetivamente o tempo de retenção celular do tempo de detenção hidráulica, havendo uma maior permanência dos microrganismos no reator.

Os primeiros reatores anaeróbios de leito fixo foram denominados filtros anaeróbios. Os estudos sobre este tipo de reator iniciaram-se com a publicação de Young \& Mccarty (1969). Eles operaram um filtro alimentado por esgoto sintético e obtiveram uma eficiência superior a $80 \%$ em termos de redução de DBO.

Diversas configuraçōes de reatores vêm sendo estudadas ao longo dos anos, no entanto as buscas por novas alternativas mais eficazes no tratamento de esgoto sanitário ainda se fazem necessárias. Nesse trabalho, a opção por reator de leito fixo aparece como uma alternativa ao reator UASB (Upflow 
anaerobic sludge blanket), que costuma apresentar problemas relacionados à perda de sólidos com o efluente e que, se comparados a outros sistemas de tratamento, tem sido bastante estudado.

A discussão sobre a utilização de processo anaeróbio ou aeróbio para o tratamento de esgoto sanitário está se tornando cada vez menos freqüente. A combinação dos dois processos tem como objetivo aproveitar as vantagens de cada processo, minimizando seus aspectos negativos. Como resultado busca-se maior remoção da matéria orgânica, características dos reatores aeróbios, contudo com baixos custos de implantação e operação do sistema, além de sistemas mais compactos com menor produção de lodo, que podem ser citados como vantagens dos sistemas anaeróbios. Além disso, a combinação torna possível a remoção de nitrogênio e, algumas vezes, fósforo.

O Brasil tornou-se um dos países líderes no mundo no uso de processos anaeróbios para o tratamento de esgoto sanitário. Isso se deve as vantagens geradas pelo seu clima favorável. Entretanto, os sistemas anaeróbios são muitas vezes incapazes de produzir efluentes que obedeçam as normas de meio ambiente impostas pela legislação brasileira. Assim, o pós-tratamento desse efluente tornou-se de suma importância, deixando a qualidade do esgoto tratado compatível com essas normas (Chernicharo et al, 2001).

O objetivo geral desse trabalho de pesquisa foi a avaliação do desempenho de um reator anaeróbio-aeróbio de escoamento ascendente e leito fixo, contendo biomassa imobilizada em espuma de poliuretano, no tratamento de esgoto sanitário. Dessa forma, esse trabalho pretende contribuir para o esclarecimento de algumas dúvidas, para a proposição de novas configurações de reatores e para o levantamento de novas questôes pertinentes a esse assunto, de forma a contribuir para pesquisas futuras nessa área.

\section{MATERIAL E MÉTODOS}

O presente trabalho teve a intenção de avaliar até que ponto a utilização do pós-tratamento aeróbio tem condição de remover o residual de matéria orgânica oriundo de tratamento anaeróbio, além de promover a nitrificação, utilizando reator de leito fixo anaeróbio-aeróbio.
Nos experimentos foi utilizado reator de leito fixo e escoamento ascendente, apresentado na Figura 1, o qual foi operado como anaeróbio ou como combinado anaeróbio-aeróbio. O leito foi dividido em quatro compartimentos de igual volume, separados por placas de PVC perfuradas, fixadas por uma haste de inox.

O reator foi construído com tubos de acrílico com diâmetro interno de $90 \mathrm{~mm}$ e $1000 \mathrm{~mm}$ de comprimento, com volume total de, aproximadamente, 6,4 L. Para evitar a incidência direta da luminosidade, o reator foi encoberto com papel alumínio.

O reator era constituído de duas partes: a câmara de alimentação e distribuição de água residuária e o leito reacional. A câmara de alimentação e distribuição de água residuária era constituída de um tubo de acrílico de
$90 \mathrm{~mm}$ de diâmetro externo e comprimento de $100 \mathrm{~mm}$, totalizando um volume de aproximadamente 0,6 L. Essa alimentação foi feita pela parte inferior do reator por meio de uma bomba dosadora peristáltica Gilson modelo Miniplus 3. O leito do reator era constituído por um tubo de $90 \mathrm{~mm}$ de diâmetro externo e comprimento de $900 \mathrm{~mm}$, totalizando um volume de aproximadamente 5,8 L.

Partículas de espuma de poliuretano (densidade aparente de $23 \mathrm{~kg} / \mathrm{m}^{3}$ e porosidade de $95 \%$, aproximadamente) dispostos em matrizes cúbicas de $1,0 \mathrm{~cm}$ de lado foram usadas como suporte de imobilização da biomassa em todos os compartimentos do reator $\left(\mathrm{P}_{1}\right.$ a $\left.\mathrm{P}_{4}\right)$, caracterizando o leito fixo do reator.

Para permitir a rápida partida do reator, foi utilizado inóculo obtido do

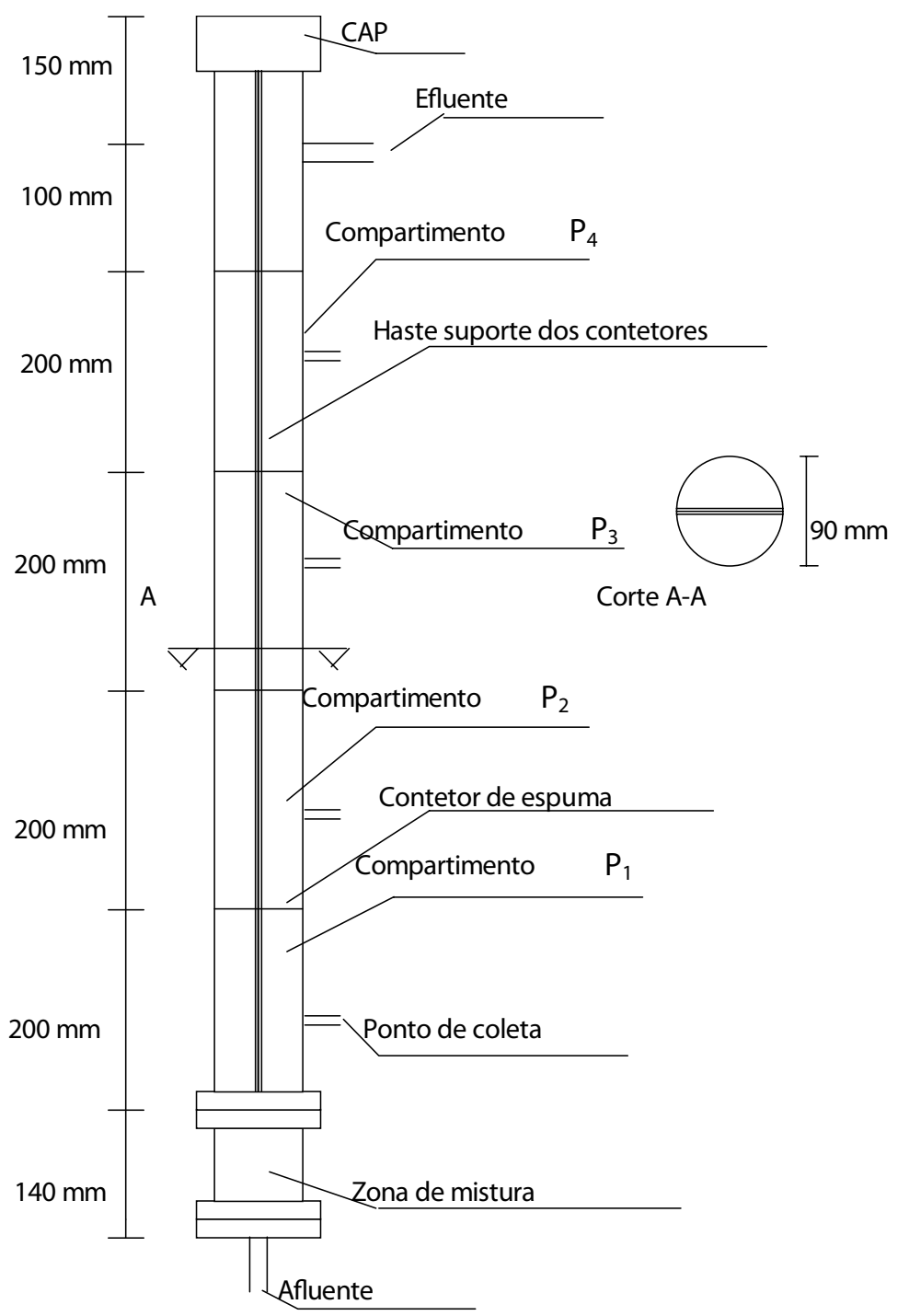

Figura I- Esquema do reator de leito fixo com escoamento ascendente e leito com espuma de poliuretano 
reator anaeróbio de manta de lodo e escoamento ascendente (UASB) tratando águas residuárias provenientes de um abatedouro de aves localizado no município do Tietê, SP. O lodo anaeróbio foi imobilizado na espuma de poliuretano conforme metodologia desenvolvida por Zaiat et al (1994).

A água residuária estudada foi obtida na Estação de Tratamento de Esgoto (ETE) do Campus da Universidade de São Paulo (USP) em São Carlos, SP. O esgoto sanitário é proveniente do Campus Universitário, que envolve restaurante universitário, banheiros e determinados resíduos de alguns laboratórios, além do esgoto sanitário de dois bairros residenciais da cidade.

$\mathrm{O}$ esgoto afluente passava por um reservatório, que funcionava como um tanque de equalização, antes de chegar ao reator. Esse reservatório consistia numa caixa com volume de 750 L e era dotada de um sistema de peneiramento na sua entrada, composto por duas telas com $2 \mathrm{~mm}$ de diâmetro, para retenção dos sólidos mais grosseiros.

Para avaliação operacional e de desempenho do reator unicamente anaeróbio foram estudados três tempos de detenção hidráulica (TDH) diferentes para avaliar a melhor condição operacional do reator. Primeiramente foi aplicado TDH de $8 \mathrm{~h}$ (Etapa 1), correspondente a uma vazão de aproximadamente $0,80 \mathrm{~L} / \mathrm{h}$. O período de operação para avaliação operacional do reator nessa condição foi de 52 dias. Após a operação com esse TDH, duas atuaçōes operacionais foram consideradas para tornar o processo mais eficiente: aumento da vazão de esgoto ou do TDH. O aumento da vazão de esgoto, embora resulte na diminuição do $\mathrm{TDH}$, provoca o aumento da velocidade de transferência de massa líquido-sólido, podendo resultar em efeitos positivos no desempenho global do processo. Dessa forma, se o material solubilizado não foi adequadamente utilizado por limitações de transferência de massa, poderia haver melhorias no processo. Por outro lado, o aumento do TDH, embora possa contribuir para a diminuição da velocidade de transferência de massa líquido-sólido, devido à conseqüente menor vazão aplicada, tem a vantagem de permitir a ocorrência de reações mais lentas.

Dessa forma, as etapas operacionais seguintes levaram em consideração essas duas hipóteses. Inicialmente o
TDH foi diminuído para 6 h (Etapa 2) por meio do aumento da vazão de água residuária para $1,07 \mathrm{~L} / \mathrm{h}$ visando, assim, aumentar a velocidade superficial de líquido no leito com o objetivo de diminuir a resistência à transferência de massa na fase líquida. O período de operação para avaliação operacional do reator nessa condição foi de 30 dias. Posteriormente, o TDH foi aumentado para $10 \mathrm{~h}$ (Etapa 3), correspondendo a uma vazão de aproximadamente $0,64 \mathrm{~L} / \mathrm{h}$, com o objetivo de verificar se essa variável era a mais significativa para o desempenho global do reator. Essa condição operacional foi mantida por 23 dias.

$\mathrm{Na}$ última condição, com o reator operando anaeróbio-aeróbio, o TDH foi aumentado para $12 \mathrm{~h}$ (Etapa 4), $6 \mathrm{~h}$ no trecho anaeróbio e $6 \mathrm{~h}$ no trecho aeróbio, pois se considerou que os resultados obtidos para o reator operando anaerobiamente com espuma em todos os compartimentos e TDH de $6 \mathrm{~h}$ foram bastante satisfatórios. $\mathrm{O} \mathrm{TDH}$ aplicado correspondeu a uma vazão de aproximadamente $0,53 \mathrm{~L} / \mathrm{h}$. O período de operação para avaliação operacional do reator nessa condição foi de 19 dias. Foi utilizado um compressor para o fornecimento de ar comprimido ao reator. A aeração foi feita no meio do reator - início do compartimento $\mathrm{P}_{3}$ - por meio de um difusor poroso e foi mantida a uma vazão constante e igual a $3 \mathrm{~L} / \mathrm{min}$.

É importante ressaltar que esses tempos de detenção hidráulica foram calculados com base no volume total do reator $(6,4 \mathrm{~L})$ para permitir a comparação com outras configurações de reatores. No entanto, os tempos de detenção reais devem ser calculados com base no volume de escoamento, descontado o volume ocupado pela biomassa. Estimativa aproximada, obtida por simples drenagem do líquido do reator, indicou porosidade de leito de $51 \%$. Nesse caso, os tempos reais estariam próximos a 3 , 4 e $5 \mathrm{~h}$ para os três TDH com operação anaeróbia e $6 \mathrm{~h}$ para operação combinada anaeróbio-aeróbio.

Durante a execução do experimento foram monitoradas as seguintes variáveis: vazão do esgoto, temperatura, DQO, pH, alcalinidade, ácidos voláteis, sólidos, NTK, nitrogênio amoniacal, nitrito e nitrato. Estes parâmetros estão de acordo com métodos descritos pelo Standard Methods (1998). A DQO foi fracionada em particulada, solúvel e coloidal pelo uso de membranas de $1,2 \mu \mathrm{m}$ e $0,45 \mu \mathrm{m}$ na filtração das amostras. As análises de nitrogênio somente foram realizadas na quarta etapa do experimento, quando se iniciou a aeração aos compartimentos superiores do reator, enquanto as demais foram realizadas durante todo o projeto.

Para quantificar a biomassa aderida ao suporte foi utilizado o método descrito por Ribeiro et al (2005). Primeiramente 5 cubos de espuma já inoculados foram transferidos para um frasco de $40 \mathrm{~mL}$. A esse frasco foram adicionadas pérolas de vidro numa quantidade quatro vezes maior em relação à massa de espuma pesada e $10 \mathrm{~mL}$ de água destilada. O frasco foi lacrado e agitado durante 20 minutos em um ângulo de $45^{\circ}$ para que a biomassa aderida se soltasse das matrizes de espuma. Em seguida separou-se o líquido das pérolas de vidro e das espumas sendo transferido para uma cápsula de porcelana previamente pesada. As pérolas foram lavadas com mais $5 \mathrm{~mL}$ de água destilada que também foram transferidos para a cápsula, que posteriormente foi mantida em estufa por 24 horas, a uma temperatura de $105^{\circ} \mathrm{C}$. Após isso, a cápsula foi levada para um dessecador até que atingissem a temperatura ambiente para ser pesada. Na última etapa, a cápsula foi colocada numa mufla a uma temperatura de $550^{\circ} \mathrm{C}$, permanecendo durante 2 horas. Por fim, pesou-se novamente a cápsula. As espumas permaneceram por 24 horas numa estufa com temperatura de $105^{\circ} \mathrm{C}$, promovendo a secagem das mesmas. Em seguida, as mesmas foram levadas para um dessecador até que atingissem a temperatura ambiente para serem pesadas.

\section{RESULTADOS E DISCUSSÃO}

Durante o período operacional, foram realizadas amostragens de 24 horas do esgoto sanitário afluente ao reator que ficava armazenado em reservatório. Nesses perfis temporais foram coletadas amostras em intervalos de 2 horas, sendo analisada a demanda química de oxigênio (DQO) de amostra bruta e filtrada. Os resultados obtidos nesses perfis mostraram que os valores da DQO afluente não variaram muito ao longo do dia para amostras brutas e filtradas no tanque de armazenamento. Dessa forma, não foi necessária a realização de amostragem composta, pois 
coletas de amostras pontuais, feitas em um horário equivalente à média de DQO do dia, já eram suficientes para obtenção de resultados condizentes com a realidade.

Ao final de todo período operacional, foram retiradas algumas amostras da espuma imobilizada para cálculo da concentração média de biomassa aderida ao suporte. Os valores encontrados foram de $0,73 \mathrm{mg} \mathrm{SVT/g}$ suporte, resultando em concentração de 3,35 g STV/L, com base no volume total do reator.

A temperatura ambiente média na sala onde estava instalado o reator utilizado no experimento foi de $20 \pm 3^{\circ} \mathrm{C}$. $\mathrm{O}$ esgoto afluente ao sistema apresentou temperatura média de $20 \pm 3^{\circ} \mathrm{C}$, enquanto o efluente teve média de $19 \pm 3^{\circ} \mathrm{C}$.

As Figuras 2 e 3 mostram as variações temporais de DQO de amostras bruta e solúvel no efluente do reator, respectivamente, variando ao longo de todo o período operacional do reator, incluindo assim as quatro etapas de operação do mesmo.

Baseado nos dados de DQO de amostras brutas pode-se verificar que o reator atingiu estabilidade operacional após 30 dias de operação aproximadamente. $\mathrm{Na}$ primeira etapa (TDH $=8 \mathrm{~h}$ ), a DQO bruta efluente apresentou valor médio de $175 \pm 35 \mathrm{mg} / \mathrm{L}$, com $288 \pm 62 \mathrm{mg} / \mathrm{L}$ afluente, resultando em uma remoção média de $37 \%$.

Com a diminuição do TDH para $6 \mathrm{~h}$ após 52 dias de operação, houve um esperado aumento na DQO efluente, mas o reator rapidamente voltou a apresentar valores baixos para esse parâmetro, aproximadamente após 74 dias. Nessa segunda etapa a DQO bruta efluente teve uma média de $214 \pm 30 \mathrm{mg} / \mathrm{L}$, com $445 \pm 1 \mathrm{mg} / \mathrm{L}$ afluente e conseqüente remoção média de $46 \%$.

Devido à diminuição nesse TDH de 8 para 6 horas, foi observado um impacto inicial no processo, mas o reator apresentou capacidade de estabilização e voltou a operar de maneira satisfatória. Se forem considerados os primeiros 7 dias de análise, as médias de DQO bruta afluente e efluente foram de $451 \pm 180 \mathrm{mg} / \mathrm{L}$ e $234 \pm 18 \mathrm{mg} / \mathrm{L}$, respectivamente. Já os 5 demais dias tiveram médias de DQO bruta afluente de $436 \pm 81 \mathrm{mg} / \mathrm{L}$ e efluente de $185 \pm 16 \mathrm{mg} / \mathrm{L}$, valor $21,0 \%$ menor que o anterior.

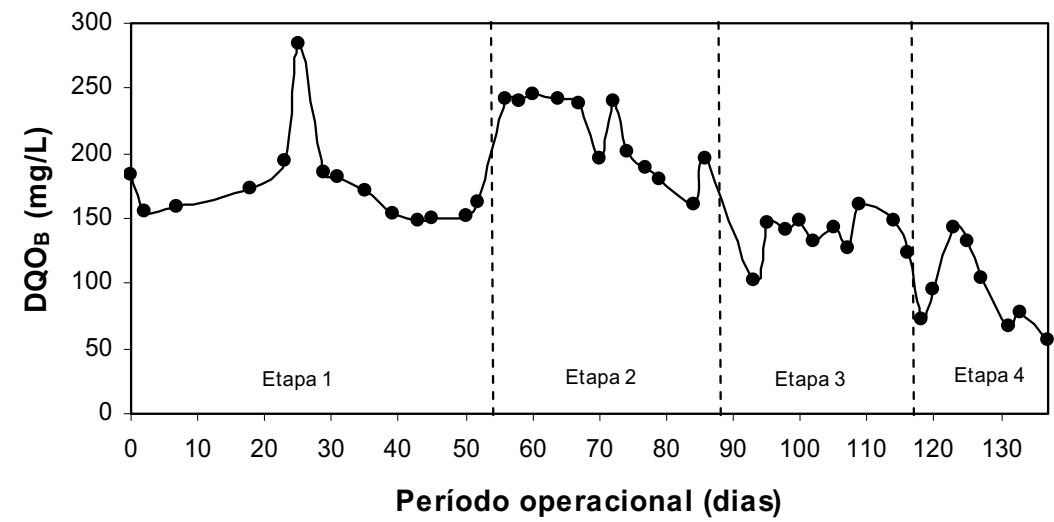

Figura 2 - Variação temporal da DQO efluentes de amostra bruta para o reator durante as quatro fases de operação. Etapa I: $T D H=8$ h, Etapa 2: TDH=6 h, Etapa 2: TDH= 10 h, Etapa 4: $T D H=I 2$ h (anaeróbio-aeróbio)

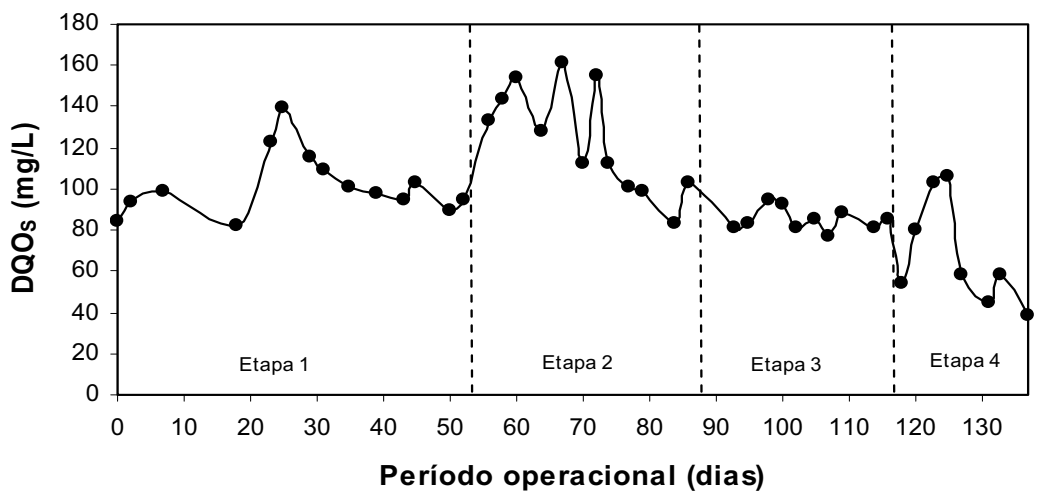

Figura 3 - Variação temporal da DQO solúvel efluente para o reator durante as quatro fases de operação. Etapa I: TDH=8 h, Etapa 2: $T D H=6$ h, Etapa 2: TDH= 10 h, Etapa 4: $T D H=I 2$ h (anaeróbio-aeróbio)

Pôde-se observar que na terceira etapa operacional a matéria orgânica foi removida eficientemente para um TDH de 10 horas. Os valores efluentes, tanto para amostra bruta como solúvel, foram praticamente constantes durante todo o período operacional. Fica evidente nessas figuras que o TDH de 10 horas ( $5 \mathrm{~h}$ com base no volume real de escoamento) conferiu maior estabilidade operacional ao reator. $\mathrm{O}$ efluente apresentou um valor médio de DQO bruta de $137 \pm 16 \mathrm{mg} / \mathrm{L}$, que se manteve independente das variaçôes da DQO bruta afluente, que apresentou média de $389 \pm 70 \mathrm{mg} / \mathrm{L}$. A remoção média foi de $64 \%$, resultado satisfatório, principalmente se comparado às condiçôes anteriores.

$\mathrm{Na}$ quarta fase operacional podese observar que a matéria orgânica foi removida eficientemente no reator com TDH de 12 horas ( $6 \mathrm{~h}$ com base no volume real de escoamento), ope- rando em condição anaeróbia seguida de aeróbia. Pôde-se observar que os valores obtidos para o efluente, tanto para amostra bruta, como para solúvel se mantiveram praticamente constantes durante todo o período operacional. $\mathrm{O}$ efluente apresentou um valor médio de DQO de amostra bruta de $93 \pm 31 \mathrm{mg} / \mathrm{L}$, que se manteve independente das variaçóes da DQO bruta afluente, com média de $259 \pm 69 \mathrm{mg} / \mathrm{L}$. É importante ressaltar que mesmo para um pico de DQO de $409 \mathrm{mg} / \mathrm{L}$ no $9^{\circ}$ dia operacional da quarta fase, o efluente apresentou um valor igual a $104 \mathrm{mg} / \mathrm{L}$, ou seja, o sistema apresentava-se operando com eficiência satisfatória, independente das variaçōes afluentes.

Com o aumento do TDH de 10 para $12 \mathrm{~h}$, o processo apresentou pequena instabilidade operacional no período inicial. Provavelmente os microrganismos anaeróbios dos com- 
partimentos $\mathrm{P}_{3}$ e $\mathrm{P}_{4}$ estavam se adaptando à nova condição operacional. No entanto, novamente o reator apresentou capacidade de estabilização e voltou a operar de maneira satisfatória. Se forem considerados os primeiros 5 dias de análise, as médias de DQO bruta afluente e efluente foram de $271 \pm 83 \mathrm{mg} / \mathrm{L} \mathrm{e}$ $109 \pm 28 \mathrm{mg} / \mathrm{L}$, respectivamente. Já os 3 demais dias tiveram médias de DQO bruta afluente de $237 \pm 42 \mathrm{mg} / \mathrm{L} \mathrm{e}$ efluente de $67 \pm 10 \mathrm{mg} / \mathrm{L}$, valor $38,5 \%$ menor que o anterior.

A avaliação do comportamento dos valores da DQO da fração solúvel no efluente indica que o material solubilizado pela hidrólise não era totalmente assimilado pela biomassa acidogênica até o $8^{\circ}$ dia de operação. A partir deste dia, os valores afluente e efluente permaneceram praticamente iguais, indicando equilíbrio dos processos de hidrólise e consumo de material solubilizado. Durante as quatro fases de operação, as médias de DQO defração solúvel no efluente foram de $102 \pm 16,124 \pm 26,85 \pm 5$ e $68 \pm 26 \mathrm{mg} / \mathrm{L}$ para as etapas $1,2,3$ e 4 , respectivamente.

A Figura 4 mostra um gráfico de barras que compara os percentuais das frações suspensa, solúvel e coloidal - afluentes e efluentes - para os diferentes TDH estudados.

Pode-se ver que para todos os TDH a remoção de DQO suspensa e coloidal foi bastante razoável. As médias de remoção de DQO suspensa foram de 75, 60, 81 e $81 \%$ para os TDH de 6, 8, 10 e 12 horas, respectivamente. Já as médias de remoção de DQO coloidal foram de 65, 68, 83 e $79 \%$ para os TDH de 6, 8, 10 e 12 ho- ras, respectivamente. Para DQO solúvel praticamente não houve remoção para os TDH de 6 e 8 horas e as médias para 10 e 12 horas foram de 16 e $45 \%$. No entanto, como a fração solúvel da DQO é produzida a partir da fração suspensa e consumida posteriormente, os valores de eficiência de remoção para essa fração devem ser analisados com cuidado.

O valor médio da concentração de sólidos em suspensão voláteis (SSV) para o afluente foi de $122 \pm 92 \mathrm{mg} / \mathrm{L}$, enquanto que as médias de concentração de SSV efluente foram de $50 \pm 36,53 \pm 34,48 \pm 17 \mathrm{mg} / \mathrm{L} \mathrm{e}$ $10 \pm 4 \mathrm{mg} / \mathrm{L}$ para as etapas $1,2,3 \mathrm{e}$ 4 , respectivamente. Fica evidente para esse parâmetro a grande melhoria na qualidade do efluente quando o reator operou com processo combinado anaeróbio-aeróbio.

Para avaliação da estabilidade do reator, foi monitorada a variação temporal da concentração dos ácidos voláteis totais (AVT). Desde o primeiro dia o valor da concentração de AVT do efluente foi menor que do afluente, indicando equilíbrio do processo de conversão anaeróbia da matéria orgânica. $\mathrm{O}$ valor médio para o afluente foi de $49 \pm 15 \mathrm{mg} \mathrm{HAc/L}$ enquanto que os valores médios para o efluente foram de $24 \pm 8,26 \pm 12,22 \pm 8 \mathrm{e}$ $29 \pm 11 \mathrm{mg} \mathrm{HAc} / \mathrm{L}$ para as etapas 1,2 , 3 e 4, respectivamente.

É interessante destacar que, na operação com TDH de 8 horas, a DQO bruta efluente foi composta principalmente por material solubilizado (aproximadamente 54\%), sendo o material particulado responsável por aproximadamente $32 \%$ do total e a coloidal por apenas $14 \%$. Do material

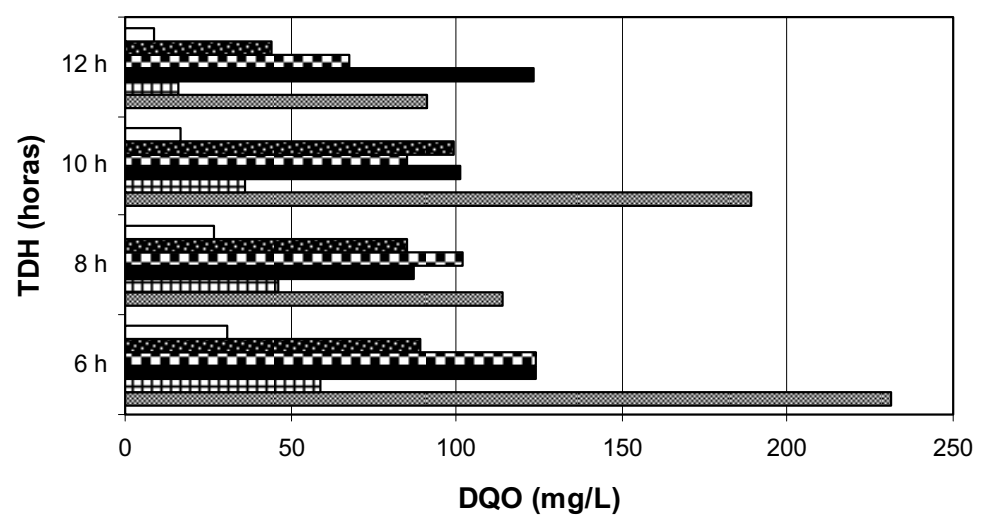

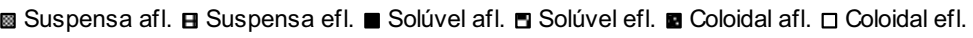

Figura 4 - Comparação entre os percentuais das frações suspensa, solúvel e coloidal - afluentes e efluentes - para os diferentes TDH solubilizado, apenas $20 \%$ aproximadamente era composto por ácidos graxos voláteis, intermediários no processo de degradação anaeróbia. No afluente, a DQO suspensa representava $41 \%$ da DQO total, enquanto que a fração solúvel e o material coloidal respondiam por aproximadamente $29 \%$ cada. Dessa forma, fica claro que o sistema foi eficiente em solubilizar material particulado, mas a utilização do material solubilizado ainda foi ineficiente.

$\mathrm{Na}$ operação com TDH de 6 horas, a DQO bruta efluente foi composta principalmente por material solubilizado (aproximadamente 58\%), valor superior ao observado para a operação com TDH de 8 horas (54\%). O material particulado responsável por aproximadamente $28 \%$ do total e a coloidal por apenas $14 \%$, valores muito próximos aos observados na operação anterior. No afluente, a DQO suspensa representava $52 \%$ da DQO total, enquanto que a fração solúvel representava $28 \%$ e o material coloidal respondia por aproximadamente $20 \%$.

A diminuição do TDH de 8 para 6 horas, com conseqüente aumento da velocidade superficial de líquido no leito e da carga orgânica aplicada não resultou em melhorias na eficiência do processo. Pelo contrário, embora o processo tenha ocorrido de forma estável, os valores de DQO bruta efluente foram superiores quando foi aplicado TDH de 6 horas. Os resultados foram similares somente em relação ao material particulado. Dessa forma, a primeira hipótese levantada, a qual postulava que um aumento das velocidades de transferência de massa líquido-sólido poderia ser fator determinante para aumento da eficiência da conversão de matéria orgânica solúvel, não foi confirmada. Partiu-se, então para a verificação da segunda hipótese, aumentando-se o TDH para 10 horas.

Os resultados indicam claramente que a condição operacional com TDH de 10 horas foi mais efetiva que as anteriores, tanto para a eficiência global do processo quanto para a estabilidade do processo de digestão anaeróbia. Nesse caso, a DQO bruta efluente foi composta principalmente por material solubilizado (aproximadamente 61\%) da mesma forma que nas operaçōes anteriores. No entanto, o valor da DQO solúvel foi bem menor nessa condição, $85 \mathrm{mg} / \mathrm{L}$ contra $102 \mathrm{mg} / \mathrm{L}$ para a operação com TDH de 8 horas 
e $124 \mathrm{mg} / \mathrm{L}$, obtida quando $\mathrm{TDH}$ de 6 horas foi aplicado. O material particulado foi responsável por aproximadamente $26 \%$ do total e o coloidal por apenas $12 \%$. No afluente, a DQO suspensa representava $49 \%$ da DQO total, enquanto que a fração solúvel e o material coloidal respondiam por aproximadamente $25 \%$ cada.

$\mathrm{Na}$ operação em sistema combinado anaeróbio-aeróbio, com TDH total de 12 horas, a DQO bruta efluente foi composta principalmente por material solubilizado (aproximadamente 62\%), indicando que, embora o valor da DQO tenha sido menor nessa condição, o material solubilizado continuou a constituir a fração predominante do efluente do reator, mesmo com a introdução da zona aeróbia. O material particulado foi, nesse caso, responsável por aproximadamente $30 \%$ do total e o coloidal por apenas $8 \%$.

Com os resultados obtidos nas operações com diferentes tempos de detenção em reator anaeróbio e no combinado anaeróbio-aeróbio, ficou demonstrado que, em todas as condições operacionais, a fração solúvel foi a mais representativa no efluente. Essa fração pode ser resultado de material solubilizado na etapa hidrolítica e não utilizado posteriormente, ou por material excretado pelas células, como os polímeros extracelulares que podem ser persistentes à degradação.

O monitoramento da alcalinidade a bicarbonato foi de grande importância não só para atestar a estabilidade operacional do reator, como também para confirmar a ocorrência do processo de nitrificação quando o reator foi operado com aeração dos módulos superiores. Em todas operações anaeróbias a alcalinidade a bicarbonato foi maior no efluente que no afluente, ocorrendo apenas o inverso na operação do sistema anaeróbio-aeróbio. $\mathrm{O}$ valor médio para o afluente foi de $143 \pm 38 \mathrm{mg} \mathrm{CaCO} / \mathrm{L}$ enquanto que os valores médios para o efluente foram de $196 \pm 43,162 \pm 19$, $165 \pm 17$ e $58 \pm 62 \mathrm{mg} \mathrm{CaCO}_{3} / \mathrm{L}$ para as etapas 1, 2, 3 e 4, respectivamente. $\mathrm{Na}$ quarta etapa operacional a alcalinidade a bicarbonato foi menor para o efluente que a observada no afluente como resultado da nitrificação biológica. Pode-se observar no último dia operacional que o valor da alcalinidade a bicarbonato caiu até aproximadamente zero. Esse comportamento foi comprovado pelas análises de nitrogênio amoniacal
(Figura 5), nitrito (Figura 6) e nitrato (Figura 7), realizadas no efluente do reator ao longo da operação combinada anaeróbia-aeróbia.

Pôde-se observar pelos valores médios afluentes $(35 \pm 6 \mathrm{mg} \mathrm{N}-\mathrm{NTK} / \mathrm{L}$ e $28 \pm 6 \mathrm{mg} \mathrm{N}$-Amon/L), que a maior parte do nitrogênio afluente encontrava-se na forma amoniacal. Esses resultados se devem ao fato de a amonificação acontecer em grande parte no reservatório afluente ao reator. Os valores médios efluentes de N-NTK e $\mathrm{N}$-Amon foram $15 \pm 8 \mathrm{mg} \mathrm{N}-\mathrm{NTK} / \mathrm{L} \mathrm{e}$ $13 \pm 8 \mathrm{mg} \mathrm{N}$-Amon/L, respectivamente. Ao final da operação, atingiram-se valores de remoção de nitrogênio amoniacal de até $85 \%$.

É possível observar que a nitrificação ocorreu rapidamente após o $5^{\circ}$ dia desde o início da aeração dos módulos superiores, mantendo-se praticamente estável até o fim dessa etapa operacional. Pode-se observar na Figura 6 que houve pequeno acúmulo de nitrito no início da operação indicando que as populaçóes produtoras e consumidoras de nitrito ainda não estavam equilibradas. No entanto, após o $10^{\circ}$ dia de operação as concentrações de nitrito se mantiveram sempre baixas, indicando equilíbrio da nitrificação. Conseqüentemente, a concentração de nitrato aumentou consideravelmente (Figura 7). No $19^{\circ}$ dia operacional as concentrações de nitrogênio amoniacal, nitrato e nitrito foram de 4,0 mg N-Amon/L, $21,9 \mathrm{mg} \mathrm{NO}_{3}^{-} / \mathrm{L}$ e $0,15 \mathrm{mg} \mathrm{NO}_{2}^{-} / \mathrm{L}$.

Verificou-se que o processo de conversão não estava limitado pela concentração de oxigênio dissolvido, pois a mesma manteve-se sempre maior que $2,6 \mathrm{mg} / \mathrm{L}$ com valor médio de $4 \pm 1 \mathrm{mg} / \mathrm{L}$. É importante ressaltar que não foi intuito do trabalho estudar uma estratégia de aeração que implicasse em custos energéticos mais baixos, no entanto pesquisas futuras podem se concentrar nesse problema.

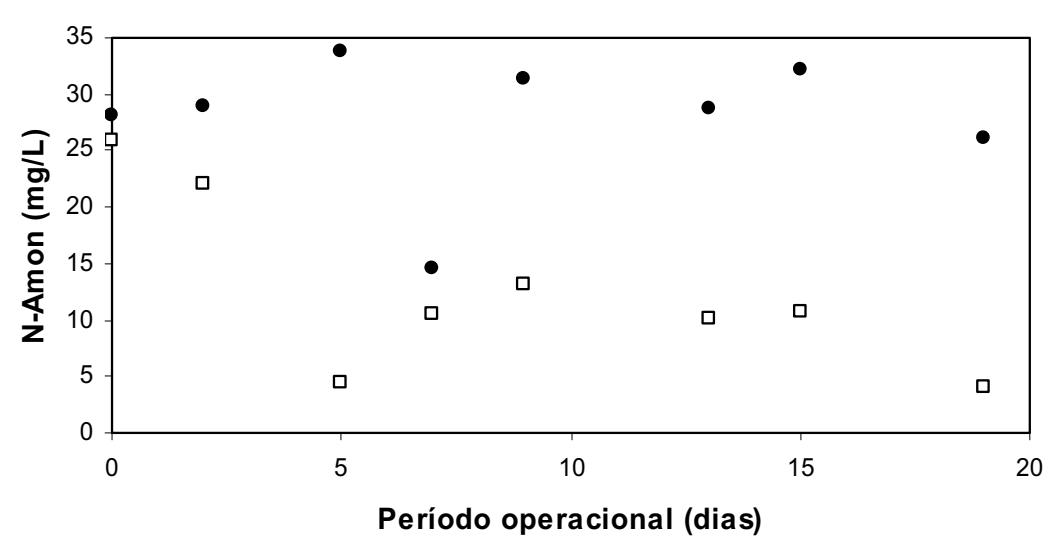

Figura 5 - Variação temporal da concentração de N-Amon afluente (•) e efluente ( $\square$ ) para o reator anaeróbio-aeróbio com TDH de I 2 h

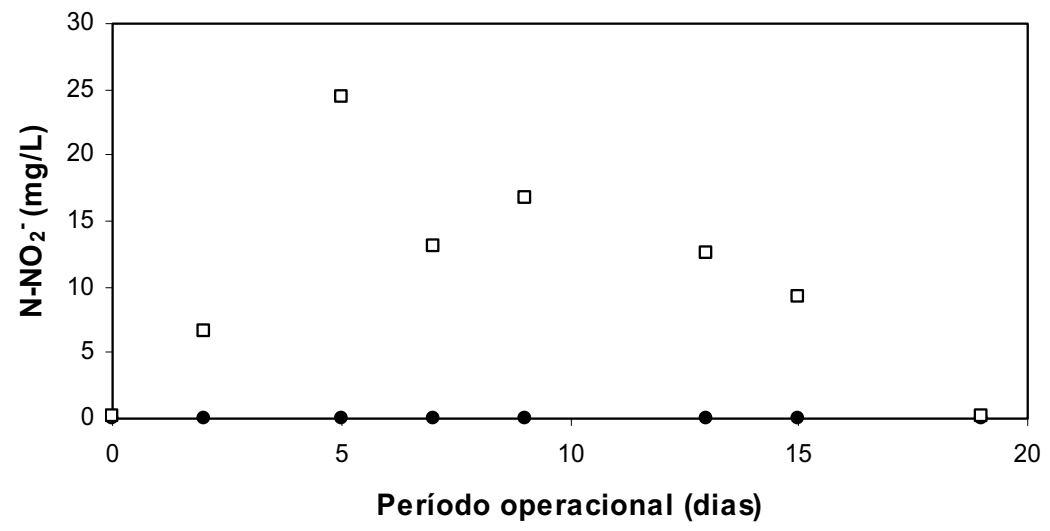

Figura 6 - Variação temporal da concentração de Nitrito afluente (•) e efluente ( $\square$ ) para o reator anaeróbio-aeróbio com TDH de I 2 h 


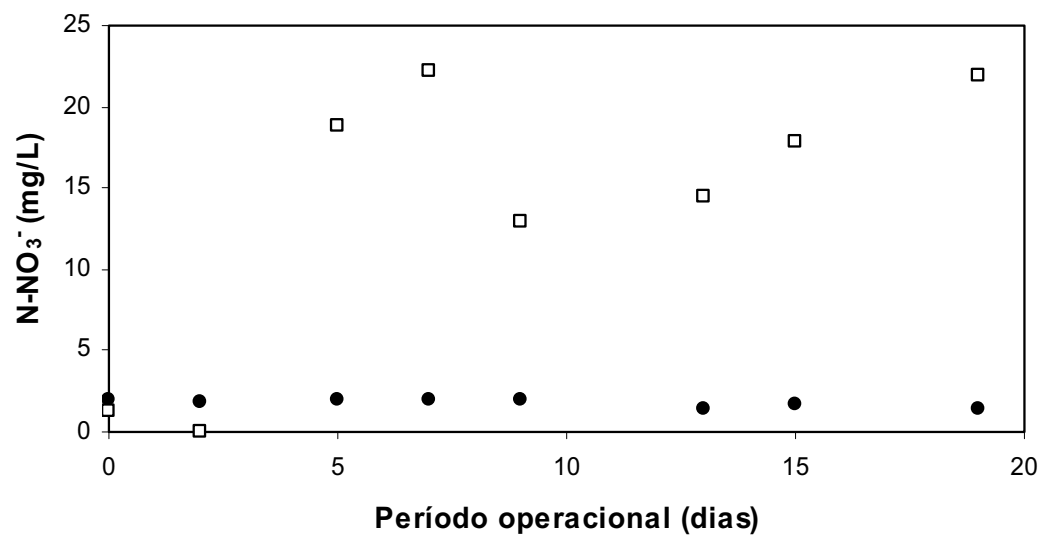

Figura 7 - Variação temporal da concentração de nitrato afluente (•) e efluente ( $\square$ ) para o reator anaeróbio-aeróbio com TDH de $12 \mathrm{~h}$

A Tabela 1 apresenta uma comparação entre os principais parâmetros de monitoramento no efluente do reator submetido a diferentes condiçôes operacionais. $\mathrm{Na}$ etapa puramente anaeróbia foi possível observar a importância do tempo de detenção hidráulica no desempenho global do processo. O aumento do TDH de 6 para 10 horas foi benéfico para o desempenho geral do sistema. No entanto, o reator apresentou estabilidade operacional sob todas as condiçôes ensaiadas. A combinação do processo anaeróbio com o aeróbio foi vantajosa não só para polimento final, com remoção da matéria orgânica remanescente, como também para nitrificação do efluente. A etapa aeróbia reduziu efetivamente a concentração total de matéria orgânica no efluente, com maior efetividade sobre a matéria orgânica solúvel e coloidal.

\section{CONCLUSÕES}

Os resultados obtidos nesse trabalho mostram a importância da utilização de novas alternativas para o tratamento de águas residuárias. Analisando-se os resultados, podem-se constatar os ganhos obtidos quando se aerou parte do reator que até então operava de maneira exclusivamente anaeróbia. No entanto, não se pode deixar de ressaltar a importância do prétratamento anaeróbio, pois ao longo do trabalho ficou evidente que a união dos aspectos positivos de cada processo traz grandes vantagens. As principais conclusões obtidas foram:

- O aumento das velocidades de transferência de massa líquido-sólido, com a diminuição do tempo de detenção hidráulica de 8 para 6 horas, não foi fator determinante para aumento da eficiência da conversão de matéria orgânica solúvel no reator anaeróbio. Ao contrário, embora o processo tenha ocorrido de forma estável, os valores de DQO bruta efluente foram superiores quando foi aplicado $\mathrm{TDH}$ de 6 horas;

- A condição operacional com tempo de detenção hidráulica de 10 horas ( $5 \mathrm{~h}$ com base no volume real) foi mais efetiva que as anteriores, $6 \mathrm{e}$ 8 horas, tanto para a eficiência global do processo quanto para a estabilidade do processo de digestão anaeróbia. Com isso foi possível verificar a importância de um adequado TDH, que se mostra a variável mais significativa para o desempenho global do reator;

- Com os resultados obtidos nas operações com diferentes tempos de detenção, ficou demonstrado que, para todas as condições operacionais estudadas, a fração solúvel foi a mais representativa no efluente do reator anaeróbio. Essa fração pode ser resultado de material solubilizado na etapa hidrolítica e não utilizado posteriormente ou de material excretado pelas células, como os polímeros extracelulares;

- Analisando-se os resultados do reator anaeróbio-aeróbio com o mesmo operando unicamente anaeróbio, podem-se constatar os ganhos obtidos quando se aerou a parte intermediária do reator no que diz respeito à remoção de matéria orgânica. Além disso, o estabelecimento de nitrificação foi efetivo, atingindo o equilíbrio operacional rapidamente.

Tabela I - Comparação das principais características do esgoto sanitário tratado no reator de leito fixo com diferentes tempos de detenção hidráulica

\begin{tabular}{ccccc}
\hline Parâmetros & \multicolumn{3}{c}{ Condição anaeróbia } & Condição anaeróbia-aeróbia \\
& 6 & 8 & TDH $(\mathrm{h})$ & $12^{*}$ \\
\hline Velocidade $(\mathrm{m} / \mathrm{h})$ & 0,17 & 0,13 & 0,10 & 0,08 \\
$\mathrm{pH}$ & $7,6 \pm 0,12$ & $7,7 \pm 0,12$ & $7,7 \pm 0,19$ & $7,5 \pm 0,75$ \\
DQO bruta afl. $(\mathrm{mg} / \mathrm{L})$ & $445 \pm 142$ & $288 \pm 62$ & $389 \pm 70$ & $259 \pm 69$ \\
DQO bruta efl. $(\mathrm{mg} / \mathrm{L})$ & $214 \pm 30$ & $175 \pm 35$ & $137 \pm 16$ & $93 \pm 31$ \\
DQO suspensa $(\mathrm{mg} / \mathrm{L})$ & $59 \pm 7$ & $46 \pm 25$ & $36 \pm 10$ & $16 \pm 8$ \\
SSV (mg/L) & $53 \pm 34$ & $50 \pm 36$ & $48 \pm 17$ & $10 \pm 4$ \\
COV $^{* *}$ (mg DQO/L.dia) & $1778 \pm 567$ & $859 \pm 186$ & $933 \pm 167$ & $517 \pm 139$ \\
\hline
\end{tabular}

*TDH de 6 horas na zona anaeróbia e 6 h na zona aeróbia.

**COV: carga orgânica volumétrica aplicada 


\section{REFERÊNCIAS}

BODIK, I. et al. Nitrogen removal in an anaerobic baffled filter reactor with aerobic post-treatment. Bioresource Technology, v. 86, p. 79-84, 2003.

CHERNICHARO, C.A.L. et al. Post-treatment of anaerobic effluents in Brazil: state of the art. IN: PROCEEDINGS OF THE 9TH WORLD CONGRESS ANAEROBIC DIGESTION ANAEROBIC DIGESTION FOR SUSTAINABILITY, vol. 1, p. 747-752, 2001.

RIBEIRO, R.; et al. Influence of the Carbon Source on the Anaerobic Biomass Adhesion on Polyurethane Foam Matrices. Journal of environmental Management, v. 74, n. 2, p. $187-194,2005$

STANDARD METHODS FOR THE EXAMINATION OFWATER AND WASTEWATE. American Public Health Association, Washington, D.C. $19^{\text {th }}$ Ed., 1998.

YOUNG, J.C; McCARTY, P.L. The anaerobic filter for waste treatment. Journal WPCF. v. 41, n. 5, p. 160-173, 1969.

ZAIAT, M.; CABRAL, A.K.A.; FORESTI, E. Reator Anaeróbio Horizontal de Leito Fixo Para Tratamento de Águas Residuárias: Concepção e Avaliação Preliminar de Desempenho. Revista Brasileira de Engenharia - Caderno de Engenharia Química, v. 11, n. 2, p. 33-42, 1994.

Endereço para correspondência:

Marcelo Zaiat

Universidade de São Paulo -USP

Escola de Engenharia de São

Carlos - EESC

Departamento de Hidráulica e

Saneamento

Av.Trabalhador São-carlense, 400

I3566-590 São Carlos - SP -

Brasil

Fax:(I6) 3373-9550 